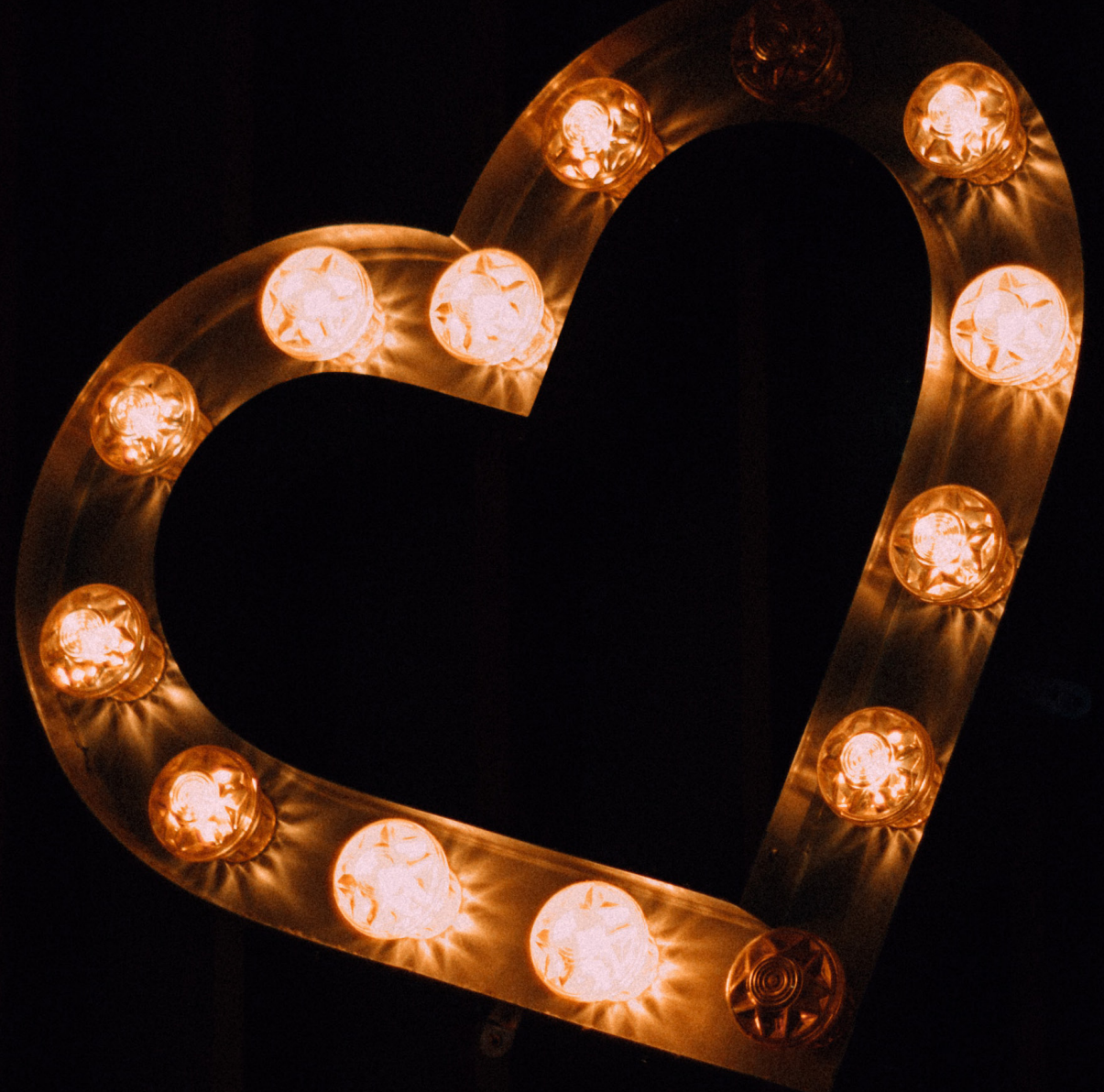

Artigo recebido em: 19/06/2017

Artigo aprovado em: 14/09/2017

DOI 10.5380/2238-0701.2017n14p43-59 
Cidade. Consumo. Midiatização. Território. 


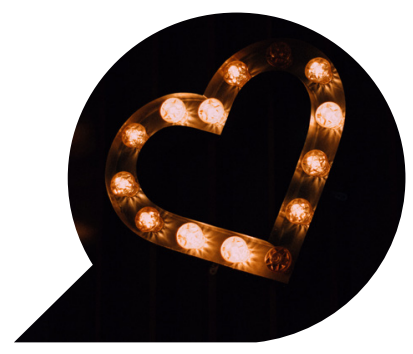

\title{
A criação de circuitos de consumo nas cidades a partir da ressignificação dos territórios urbanos
}

\author{
The creation of circuits of consumption in cities \\ through the resignification of urban territories
}

La creación de circuitos de consumo en las ciudades mediante la resignification de territorios urbanos

\section{SÉRGIO ROBERTO TREIN *}

Resumo: Especialmente na última década, uma quantidade considerável de ações e iniciativas coletivas passou a ocupar territórios como ruas, avenidas, praças, parques e terrenos vazios nas cidades. Os territórios ocupados por estas ações são espaços públicos, muitas vezes, degradados ou esquecidos, com os quais não se criam memórias afetivas e sem um uso maior dentro do contexto urbano. Através destas ações, busca-se uma recriação e uma ressignificação do território. Como parte deste processo, a midiatização ocupa um papel importante nesta tarefa de ressignificação, para que a sociedade possa interagir e gerar as articulações e as fricções necessárias. Através do estudo de cinco ações coletivas, o objetivo deste estudo será o de compreender de que forma novos processos de midiatização podem promover a ressignificação de territórios urbanos.

* Doutor em Comunicação Sociopolítica. Pós-Doutorando em Comunicação pela ECA/USP. Coordenador do curso de Publicidade e Propaganda na Universidade do Vale do Rio dos Sinos (UNISINOS. 
Palavras-chaves: Cidades; Consumo; Midiatização; Ressignificação; Território.

Abstract: Particularly during the last decade, a considerable amount of collective actions and initiatives has occupied territories such as avenues, squares, parks, and empty terrains in the cities. The territories occupied by these actions are often public spaces, degraded or forgotten, in which no affective memories are created, and which have no greater use in the urban context. The purpose of these actions is a recreation and resignification of the territory. As a part of this process, mediatization occupies an important role in this task of resignification, so that society can interact and generate the necessary articulations and frictions. Through the study of five collective actions, the objective of this study will be to understand how new processes of mediatization can promote the resignification of urban territories.

Key-words: Cities; Consumption; Mediatization; Resignification; Territory.

Resumen: Especialmente en la última década, una cantidad considerable de acciones e iniciativas colectivas pasó a ocupar territorios como calles, avenidas, plazas, parques y terrenos vacíos en las ciudades. Los territorios ocupados por estas acciones son espacios públicos, muchas veces, degradados o olvidados, con los que no se crean memorias afectivas y sin un uso mayor dentro del contexto urbano. A través de estas acciones, se busca una recreación y una resignificación del territorio. Como parte de este proceso, la mediación juega un papel importante en esta tarea de resignificación, para que la sociedad pueda interactuar y generar las articulaciones y las fricciones necesarias. A través del estudio de cinco acciones colectivas, el objetivo de este estudio será el de comprender de qué forma nuevos procesos de mediatización pueden promover la resignificación de territorios urbanos.

Palabras clave: Ciudades; Consumo; Mediatización; Reignificación; Território. 


\section{Introdução}

As cidades sempre mexeram com a imaginação popular. Em todos os momentos da vida, seja na infância, na adolescência, na fase adulta e, mesmo na fase madura, em algum instante, de alguma forma, as pessoas criam relações emocionais e de raízes com as suas cidades e têm, guardadas em suas memórias, alguma lembrança especial do lugar onde moram ou moraram um dia. Segundo o psicanalista James Hillman (1993), que estuda as cidades sob o ponto de vista dos arquétipos, das imagens e dos símbolos, estas acontecem porque a cidade está na alma das pessoas.

Conforme o autor, esta ligação entre alma e cidade pode ser identificada através de vários aspectos. $\mathrm{O}$ primeiro deles se manifesta pela ideia de reflexão, conforme Hillman (1993). E isso está construído em nossas cidades sob a forma de piscinas, lagos, galerias, sombras e janelas onde ocorrem reflexos. Ou seja, as pessoas precisam se enxergar nos espelhos da cidade e, assim, perceber a sua alma presente no espaço urbano. Um segundo aspecto está ligado à ideia de profundidade. Precisamos de níveis, tais como níveis de iluminação ou de materiais contrastantes, para que possamos nos perceber e nos localizar na cidade. Um terceiro ponto, que evidencia esta ligação entre alma e cidade, de acordo com Hillman (1993), é que a alma tende a ser imaginada por meio de imagens e símbolos. Sem imagens, complementa o autor, corremos o risco de perder o caminho. Isso acontece, por exemplo, nas ruas e nas estradas, através das placas.

A alma precisa tanto de imagens que, quando não as encontra, elabora substitutos, como os cartazes de rua e os grafites, por exemplo. Porém, um dos aspectos mais importantes que explicam esta ligação da alma com as cidades é a ideia de que alma tem a ver com memória emotiva. Como afirma Sanchés (2001, p. 18), "as pessoas transitam pelo território, de forma repetitiva ou não, e, assim, criam uma identidade e uma relação com o lugar”. Entretanto, segundo Ferrara (1986, p. 19), mesmo que de forma individual, "não se pode pensar ruas, praças, avenidas, passeios, casas ou prédios como elementos autônomos, mas como fatores de um conjunto". Ou seja, a cidade, prossegue a autora, é resultado da atividade do conjunto que dinamiza suas estruturas e, a isso, denominamos de contexto urbano.

É justamente esse contexto urbano que contribui para o significado da cidade. Bem como, toda mudança no contexto implica alteração da- 
quele significado. (FERRARA, 1986). Isso ocorre, complementa a autora, porque mesmo entendida como unidade de percepção, a cidade não é um dado, mas, sim, um processo contextual onde tudo é signo, é linguagem. Ruas, avenidas, praças, monumentos, edificações configuramse como uma realidade sígnica que informa sobre seu próprio objeto: isto é, o contexto. O elemento que aciona essa percepção global e contínua, que estabelece seleções e relações em um repertório contextual é o usuário e o uso é sua fala, sua linguagem. O uso é uma leitura da cidade na relação humana das suas correlações contextuais. Logo, uma praça, por exemplo, só encontra seu espaço contextual no momento em que é flagrada numa seleção de usos que lhe atribui significado.

O mesmo vale para outros elementos do mobiliário urbano. O usuário processa a leitura do mutante espaço contextual, ao mesmo tempo, que nele inscreve sua linguagem: o uso que flagra e é flagrado na cidade (FERRARA, 1986). Isso faz com que cada indivíduo, através de sua alma, de sua linguagem e de seu contexto, de acordo com Canevacci (1993), perceba no urbano, ao mesmo tempo, imundícies e êxtases, atrações e repulsões. A justificativa para este fenômeno está no fato de que, na cultura urbana, cada um comunica-se com edifícios, ruas, árvores, lojas, pontes, cenários, ambientes etc, conforme seus próprios interesses, suas relações com o território e da sua maneira (CANEVACCI, 1993).

$\mathrm{Na}$ verdade, a própria configuração do espaço urbano contribui para isso, pois a paisagem urbana pode ser definida como a percepção individual, espacial e temporal da composição de todos os seus elementos fixos (edificações, árvores, pavimentação, ruas), semifixos (anúncios, comércio ambulante) e móveis (automóveis, pessoas) (MENDES, 2006). Para Carlos (1994), todo esse contexto urbano acaba tornando-se um locus dinâmico de atividades, exercidas por pessoas, de acordo com suas necessidades sociais.

Quando se fala no contexto urbano, complementa a autora, devemos analisá-lo através de dois pontos de vista: primeiro, tomando como base uma categoria a quem denominamos de produtor, que necessitará de equipamentos de infraestrutura, de informação, de inovação, de amplas instalações. Em geral, quem ocupa este papel de produtor nas cidades são os gestores públicos. O segundo ponto de vista diz respeito a quem classificamos como consumidor, que usará o espaço fundamentalmente por questões de sobrevivência: o habitar e o trabalho, mas que para tal necessita de equipamentos de lazer, oferecimento de determinados bens e serviços coletivos, de cultura etc. 
Este espaço, em que os indivíduos acabarão conformando sua identidade e suas relações de poder, é definido como território. Necessariamente, o território não possui fronteiras visíveis. Nem mesmo o processo de formação territorial ocorre por meio de expressões concretas sobre o espaço. Pode haver, inclusive, múltiplas territorialidades no mesmo espaço. Bem como os territórios podem possuir um caráter cíclico, que varia com o tempo; móvel, que se desloca nos mais diferentes espaços; ou que se organiza a partir de redes interligadas pelo fluxo de informações ou contatos.

Tudo vai depender da relação dos indivíduos com o território e de que forma eles percebem os artefatos e como eles os utilizam como mediadores na interação com outras pessoas e seus ambientes físicos e sociais. Desta forma, passa-se a gerenciar o território como um sistema-produto, tratando dos seus aspectos materiais e imateriais e gerando sentido e valor para o espaço em si, os produtos e a cidade como um todo (REYES e FRANZATO, 2009). Especialmente quando há uma recriação do território ou intervenções urbanas que ressignifiquem este espaço.

Especialmente na última década, uma quantidade bastante considerável de ações e iniciativas coletivas passou a ocupar territórios como ruas, avenidas, praças, parques, áreas verdes e terrenos vazios nas cidades. Os territórios ocupados por estas ações são espaços públicos, muitas vezes, degradados ou esquecidos, com os quais não se criam memórias afetivas e sem um uso maior dentro do contexto urbano. No máximo, são territórios que se apresentam como um ponto ou marco nodal dentro da cidade. Todas estas ações coletivas, desenvolvidas nestes territórios, tais como os food-trucks, espaços móveis de comércio de alimentos; as novas perspectivas de ambiência, circulação e interação de mensagens produzidas pelo coletivo e promovidas através de novos moldes de sinalização e publicização destas mensagens; as intervenções artísticas; a criação de hortas comunitárias; além de cursos livres, shows e teatros nas praças e nas ruas das cidades, representaram uma ressignificação dos territórios, transformando-os em sistemas-produto.

Ou seja, procuram recriar as cidades construídas pelas almas dos indivíduos, em resposta a uma profunda crise de desconfiança em relação aos governantes, que não conseguem cumprir o seu papel estabelecido no contrato social e, por consequência, gerar sentido e valor para os espaços públicos. Com isso, a comunicação urbana produzida pelos usuários dos territórios e veiculada no próprio mobiliário urbano, bem como a comunicação veiculada nas redes sociais para gerar a mobilização social necessária 
e atrair os usuários para as ações desenvolvidas nos territórios, permite que as práticas sociopolíticas ganhem uma nova dinâmica e uma intensividade e diversidade de processos.

Ou seja, cria-se uma ruptura com os tradicionais canais de comunicação nas cidades, tais como a grande mídia, que escolhe de que parte da cidade quer falar e comunicar. $\mathrm{O}$ resultado destes novos processos de midiatização nas cidades possibilita uma alteração nos regimes de expressão e de interação sociopolítica, a partir de lógicas, operações e estratégias comunicacionais que instalam na sociedade um novo regime de estruturação de vínculos. Desta maneira, estas mídias e formatos alternativos de comunicação produzidos pelos usuários dos territórios deixam de se constituir apenas como um campo e assumem um papel de reordenação, de reorganização e de transformação na estrutura social e política.

Com base nisso, nosso estudo se enquadra no campo das metodologias qualitativas, que são caracterizadas pela descrição, compreensão e interpretação de fatos e fenômenos. Sendo ainda mais específico, as pesquisas qualitativas têm, por objetivo, investigar o significado das relações humanas e sociais, tornando possível compreender os fenômenos com dados não quantificáveis. Entre as opções de pesquisa existentes, nossa escolha foi pela pesquisa exploratória e empírica, por convidar o pesquisador a voltar o seu olhar para acontecimentos de práticas, processos e circuitos, na tentativa de estabelecer um contato maior com a situação pesquisada, para descrever e perceber fenômenos a ela relacionados.

Através da pesquisa exploratória e empírica, o objetivo deste estudo será o de compreender de que forma é possível (e se é, de fato, possível) promover a ressignificação destes territórios urbanos através de novos processos de midiatização. Para isso, como corpus de pesquisa, serão analisadas cinco ações de ressignificação dos territórios: "Que ônibus passa aqui", "Passo a passo", "Paraíso do golfe", "Dorme com essa" e "A natureza recarrega”.

\section{A criação de circuitos}

A conjunção de dois fatores, o surgimento dos meios de comunicação de massa e o intenso processo de urbanização, acabou criando quatro modelos de comunicação, no sentido de aproximar os indivíduos das sociedades, de acordo com Miège (1998). O primeiro deles foi a imprensa de opinião, especialmente de oposição aos governos. $\mathrm{O}$ segundo 
modelo veio através da expansão da imprensa, de caráter mais comercial e mais voltado às massas. Com os meios audiovisuais, como o cinema, o rádio e a televisão, formou-se um terceiro modelo. Por fim, o quarto e mais atual modelo surgiu com a ideia de comunicação generalizada, que permite fluxos de toda a ordem.

Complementando o pensamento de Miège (1998), Braga (2006) afirma que assim como, desde o século XVII, a imprensa se desenvolveu como um componente estruturante da sociedade, na medida em que esta buscava organizar, diversificadamente, as potencialidades da escrita a serviço de seus interesses múltiplos e frequentemente contraditórios; assim também vemos os processos de internacionalidade midiatizante estimulando os modos pelos quais a sociedade se comunica e, em consequência, tentativamente se organiza.

Seja naquele período ou nos dias atuais, mudam as tecnologias, mas não as principais características dos processos de midiatização. Ou seja, de que a midiatização possibilita uma alteração nos regimes de expressão e de interação sociopolítica, a partir de lógicas, operações e estratégias comunicacionais que instalam na sociedade um novo regime de estruturação de vínculo. Desta maneira, as mídias deixam de se constituir apenas como um campo e assumem um papel de reordenação, de reorganização e de transformação na estrutura social e política (VERÓN, 1997).

Mesmo com o seu papel reordenante, conforme Braga (2006), não podemos restringir o termo midiatização e nem condicioná-lo a sua penetração tecnológica. Como argumenta o autor, claro que se trata de um insumo relevante, porém entende-se que os processos comunicacionais associados não decorrem simplesmente da invenção tecnológica. É preciso um componente diretamente social no processo. Com a midiatização crescente dos processos sociais em geral, o que ocorre é a constatação de uma aceleração e diversificação de modos pelos quais a sociedade interage com a própria sociedade. Ou, como define Martín -Barbero (2009), seriam as mediações comunicativas da cultura, pois, na sociedade em midiatização, não são os meios, ou as tecnologias ou, ainda, as indústrias culturais que produzem os processos - mas sim todos os participantes sociais, grupos ad-hoc, sujeitos e instituições que acionam tais processos e conforme os acionam.

É bem verdade que o surgimento das novas tecnologias, da forma crescente como se observa nos dias de hoje, disponibiliza uma série de oportunidades de midiatização para os chamados setores não midiáticos, 
das mais diversas instituições, aos grupos ad-hoc e ao indivíduos. Na grande maioria das vezes, segundo Braga (2006), as ações desenvolvidas através destas tecnologias não se restringem ao objeto meios e nem mesmo ao objeto receptores e suas mediações. Para o autor, tais ações incluem receptores e suas mediações, em formações muito diversificadas e, ainda, articulados a outras formações.

Além de não se limitar às tecnologias puramente como objeto, o importante, também, é que estes processos produzam algum tipo de ação interacional entre os indivíduos. Nestas relações, agora compreendidas como bem mais complexas, entre a produção e a recepção, um conceito inicialmente restrito a esse intervalo entre os polos, ganha vigor e relevância, como afirma Braga (2006). Trata-se da circulação das mensagens e sentidos posterior à recepção. Para o autor, o sistema de circulação interacional, mencionado anteriormente, é justamente essa movimentação social dos sentidos e dos estímulos produzidos pelos meios.

$\mathrm{Na}$ mesma linha de raciocínio, Fausto Neto (2010, p. 11) soma-se a Braga e argumenta que a circulação é, então, "transformada em lugar no qual produtores e receptores se encontram em jogos complexos de oferta e reconhecimento". Tais jogos, complementa o autor, trazem consigo a questão dos contratos que são estabelecidos para descrever as possibilidades de construção de vínculos entre produção/recepção. Um dos elementos resultantes deste contrato é o produto. Ou seja, o momento mais esperado da circulação, pois, consolidado em sua forma e que se multiplica, pode continuar circulando e repercutindo em outros espaços.

Este não apenas é um dos preceitos do conceito de midiatização, como também é uma confirmação da definição de Braga (2006) de que a midiatização não depende exclusivamente da questão tecnológica. Tanto é assim que o que chamamos neste estudo de novos processos de midiatização nas cidades não tem absoluta nada a ver com a tecnologia e, sim, com a circulação e a construção de vínculos entre produção e recepção. Estes novos processos de midiatização, para que realmente se confirmem e tenham efeito, possam interagir na sociedade e gerar as articulações e as fricções necessárias, partem, obrigatoriamente, por processos experimentais (BRAGA, 2006), como veremos mais adiante.

Neste sentido, seja para fazer de outro modo as mesmas coisas ou para acionar processos antes não viáveis e nem sequer pensáveis, todos os setores da sociedade acabam sendo instados a se articularem através de circuitos pouco habituais (BRAGA, 2007). Segundo o autor, na prática é o que encontramos: circuitos. Cada setor ou processo da sociedade 
participa de múltiplos circuitos. Como afirma Braga (2007), com a midiatização crescente, os campos sociais, que antes podiam interagir com outros campos, segundo processos marcados por suas próprias lógicas e por negociações mais ou menos específicas de fronteiras, são crescentemente atravessados por circuitos diversos.

Esses circuitos contemporâneos, complementa o autor, envolvem momentos dialógicos, momentos especializados e momentos tecnodistanciados, todos muito difusos. Porém, o que há de comum entre todos eles, prossegue Braga (2007), é que a cultura da midiatização em implantação se faz, de fato, por experimentação. Por isso entendemos como relevante o nosso objeto de pesquisa. Porque eles criam circuitos, estão articulados com os processos de comunicação e são, efetivamente, caracterizadores da interação. No caso do nosso estudo, é justamente essa interação que leva à ressignificação dos territórios urbanos.

\section{A ressignificação dos territórios urbanos}

No sentido de gerenciar o território como um sistema-produto, tratando dos seus aspectos materiais e imateriais e gerando sentido e valor para o espaço em si, os produtos e a cidade como um todo, na cidade de Porto Alegre, foram criadas cinco ações de ressignificação dos territórios: "Que ônibus passa aqui", um projeto de sinalização colaborativa de pontos de ônibus; "Passo a passo", um projeto de sinalização para informar a distância a pé até os principais pontos da cidade e, com isso, tentar diminuir o trânsito de carros; "Paraíso do golfe", para mostrar o péssimo estado das ruas da cidade; "Dorme com essa", uma coleção de frases famosas de pessoas, promovendo questionamentos pelos muros, postes e tapumes na cidade; e "A natureza recarrega", um espaço móvel em que a pessoa pode sentar, descansar e recarregar a energia do corpo e do celular.

Cada uma delas será apresentada melhor, a seguir. Veremos que o objetivo destas ações é o de promover a ressignificação de territórios urbanos através de novos processos de midiatização, considerados como circuitos que, conforme Braga (2006), permitem a circulação e a construção de vínculos entre produção e recepção.

A ação "Que ônibus passa aqui" atende a um problema que acontece na maioria das cidades brasileiras e que, em Porto Alegre, não é diferente. Ou seja, em praticamente todos os pontos e paradas de ônibus não existe sinalização informando sobre que ônibus passa naquele trajeto. A falta de 
informação faz com que as pessoas percam tempo esperando uma linha que talvez nem passe naquela rua. Para resolver o problema, foram criados adesivos com a pergunta "Que ônibus passa aqui?" e um espaço em branco para que as pessoas preencham, colaborativamente, com as linhas que passam no local.

Figura 1: Ação "Que ônibus passa aqui?"

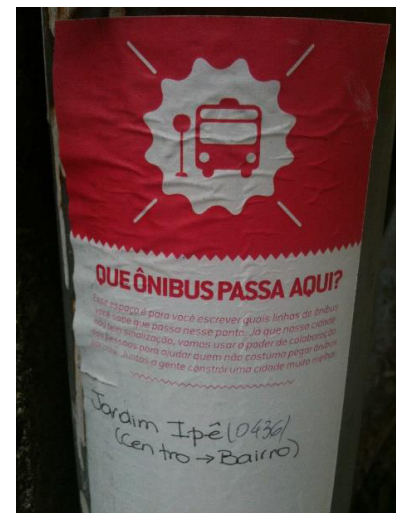

Fonte: Disponível em: http://www.shoottheshit.cc/qopa

A segunda ação, "Passo a passo", é um projeto de sinalização para informar a distância a pé até os principais pontos de Porto Alegre.

Figura 2: Ação "Passo a passo"

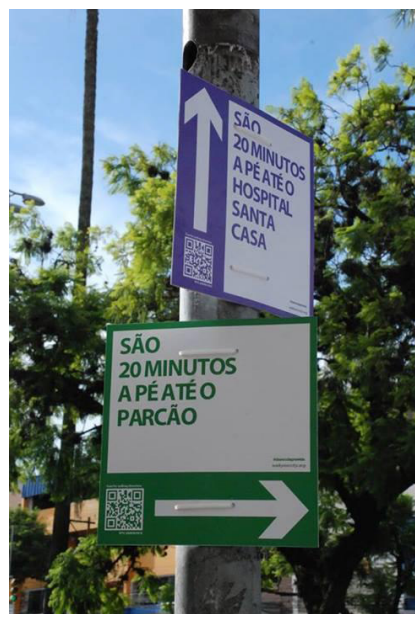

Fonte: Disponível em: http://www.shoottheshit.cc/daescolapravida 
Para mostrar o péssimo estado das ruas de Porto Alegre, o asfalto esburacado destas vias foi transformado em um grande campo de golfe. Como parte da ação, jogadores vestidos como golfistas, carregando tacos e bolas de golfe de verdade, caminhavam por ruas dos bairros mais nobres da cidade jogando golfe nos buracos do asfalto. $\mathrm{O}$ vídeo, que mostrava a ação "Paraíso do golfe", viralizou rapidamente, especialmente com o apoio dos moradores da cidade ao projeto. Como consequência da ação, a Prefeitura de Porto Alegre decidiu tapar todos os buracos que apareciam no vídeo.

Figura 3: Ação "Paraíso do golfe"

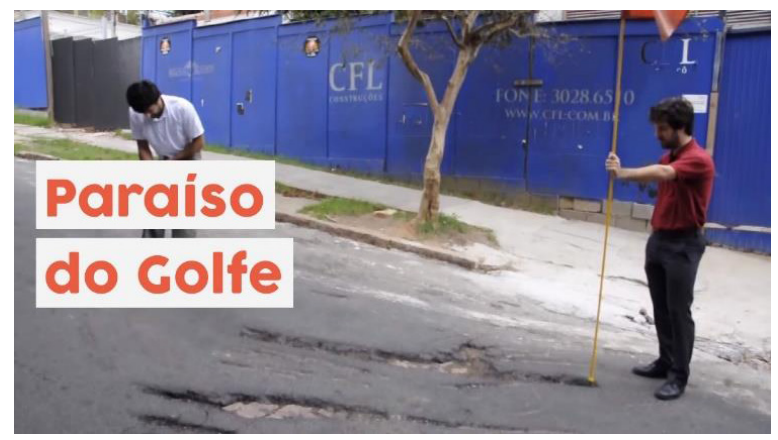

Fonte: Disponível em http://www.shoottheshit.cc/projetos/

A quarta ação, chamada "Dorme com essa", é uma coleção de frases cujo objetivo é espalhar questionamentos pelos muros, postes e tapumes na cidade. São frases de pessoas famosas que tratam sobre diversos assuntos: empreendedorismo, coragem, atitude. Elas servem como estímulo para as pessoas em um ambiente urbano que, como afirma Canevacci (1993), mescla percepções, ao mesmo tempo, de imundícies e de êxtases, de atrações e de repulsões. Toda semana, são coladas novas frases.

Figura 4: Ação "Dorme com essa”

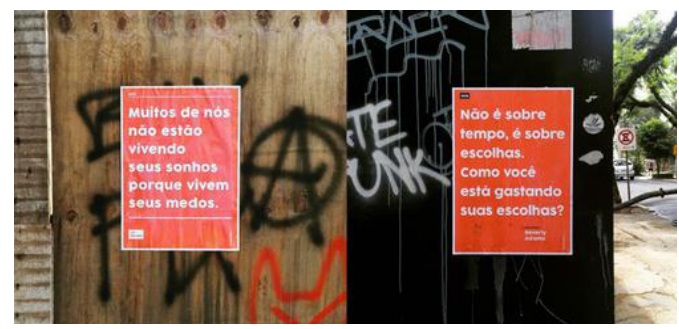

Fonte: Disponível em http://www.shoottheshit.cc/projetos/ 
A quinta ação analisada neste estudo chama-se "A natureza recarrega". Trata-se de um carrinho móvel, em forma de jardim, com grama e algumas plantas verdes, onde a pessoa pode sentar. É uma ação simples. Embora existam os parques e as praças nas cidades, nem sempre os indivíduos têm tempo suficiente para frequentar estes espaços. E, muitas vezes, o contato com a natureza pode repor as energias necessárias para a rotina das pessoas, sobretudo aquelas que residem nas cidades grandes, cercados de muros e prédios cinzentos. Dentro deste carrinho móvel, existem, também, carregadores de celular. Ou seja, além de recarregar as energias do corpo, as pessoas, naquele momento, também podem recarregar seus aparelhos celulares.

Figura 5: Ação "A natureza recarrega"

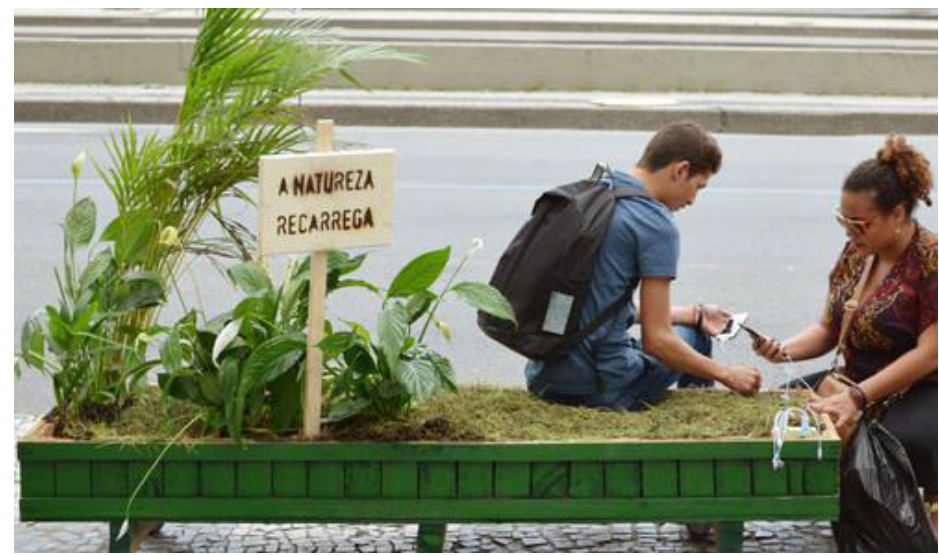

Fonte: Disponível em http://www.shoottheshit.cc/projetos/

Todas as ações reforçam a ideia de Hillman (1993), de que há uma relação entre cidade e alma e, também, de que as pessoas criam relações emocionais e de raízes com as suas cidades. Da mesma forma, podemos afirmar que existe, sim, uma relação entre os indivíduos e o território, a partir do tratamento do território como um sistema-produto, que gere sentido e valor para o espaço em si, os produtos e a cidade como um todo. Seja informando as linhas de ônibus que passam naquele trecho, sinalizando as distâncias a pé entre um ponto e outro, chamando a atenção para os buracos nas ruas, motivando as pessoas para a sua vida urbana através de frases ou oferecendo uma oportunidade de contato com a natureza, cada uma destas ações evidencia, também, o distanciamento dos indivíduos com as instâncias políticas. 
A desconfiança das pessoas, grupos determinados coletivos nestas instâncias políticas acaba gerando novos processos de midiatização. Ainda que não sejam exatamente novos em sua essência e como instrumentos de comunicação, podem ser considerados novos em sua função de circulação e circulação de vínculos na sociedade. Fugindo, inclusive, dos tradicionais gêneros e formatos de comunicação utilizados pelas instâncias políticas.

Obviamente, o objetivo destas ações e de seus processos de midiatização não é o de estabelecer uma concorrência à comunicação pública dos governos. Mas, sim, proporcionar que a sociedade se articule através de circuitos. Cada uma das ações apresentadas é um circuito caracterizador de interações. No caso deste estudo, interações que levam à ressignificação dos territórios urbanos.

\section{Considerações finais}

Embora Braga (2006) afirme que a midiatização não depende exclusivamente da questão tecnológica, é inegável que o domínio da tecnologia e das condições de produção favoreça o surgimento de novos processos de midiatização. Muitas vezes, nem tão novos assim, mas que acabam se reinventando conforme as articulações e as fricções necessárias. Sobretudo nas cidades, e, sobretudo ainda nas cidades maiores, onde as repulsas e as imundícies, definidas por Canevacci (1993), se sobressaem em maior grau. É a relação das pessoas com as cidades, das almas destes indivíduos com as cidades, por suas relações emocionais e de raízes, que faz com que se criem determinados circuitos interacionais.

Abraham Moles é um autor que dedicou seus estudos à figura do cartaz e sua condição de pertença nas cidades. Segundo o autor, a civilização contemporânea é a civilização da imagem. Entre as funções do cartaz, de acordo com Moles (1974), está a da informação, de tornar público, de fazer saber; a de publicidade ou propaganda; a de ser educadora; a da ambiência; a da questão estética; e, por fim, a de exercer uma criadora, por se tornar o campo dos possíveis e estimular a criação e a produção. Ainda que nem todos sejam cartazes, por suas características comunicacionais de gênero e de formato, pode-se afirmar que todas as ações analisadas cumprem exatamente o mesmo objetivo do cartaz. É como se afirmássemos que estes novos processos de midiatização nos territórios e nas cidades fossem grandes cartazes, pois têm as mesmas funções de um cartaz. Em especial, a da circulação das mensagens. 
Com a crescente desconfiança dos indivíduos em relação às instituições políticas devido às constantes notícias e denúncias de irregularidades e corrupção na política brasileira, pela desilusão e descrença nos políticos e pela ineficiência das administrações públicas em resolver e atender às demandas da sociedade, é possível perceber uma transição da sociedade dos meios para a sociedade de midiatização. Os novos processos de midiatização nas cidades, através da criação de circuitos de interação, acabam se mostrando mais eficientes, tanto em termos de visibilidade, como de engajamento, de resultados e, principalmente, na ressignificação dos territórios urbanos e na geração de sentido e valor para o espaço em si.

\section{REFERÊNCIAS}

BRAGA, José Luiz. A sociedade enfrenta sua mídia: dispositivos sociais de crítica midiática. São Paulo: Editora Paulus, 2006.

. Midiatização como processo interacional de referência. In: MÉDOLA, Ana Sílvia; ARAUJO, Denize Correa; BRUNO, Fernanda (Org.). Imagem, visibilidade e cultura midiática: livro da XV Compós. Porto Alegre: Sulina, 2007.

CANEVACCI, Massimo. A cidade polifônica: ensaio sobre a antropologia da comunicação urbana. São Paulo: Studio Nobel, 1993.

CARLOS, Ana Fani Alessandri. A (re)produção do espaço urbano. São Paulo: EDUSP, 1994.

FAUSTO NETO, Antonio. A circulação além das bordas. In: FAUSTO NETO, Antonio; VALDETTARO, Sandra (Org.) Mediatización, Sociedad y Sentido: diálogos entre Brasil y Argentina. Rosario, Argentina: Departamento de Ciências de la Comunicación, Universidad Nacional de Rosario, 2010. p. 2-15. Disponível em: $<$ http://www.fcpolit.unr.edu.ar/wpcontent/uploads/Mediatizaci\%C3\%B3n-sociedady-sentido.pdf $>$. Acessado em 30 de outubro de 2016.

FERRARA, Lucrécia D'Aléssio. A estratégia dos signos. 2a . edição. São Paulo: Editora Perspectiva, 1986.

HILLMAN, James. Cidade \& alma. São Paulo: Studio Nobel, 1993. 
MARTÍN-BARBERO, Jesús. Uma aventura epistemológica. Entrevistador: Maria Immacolata Vassallo de Lopes. Matrizes, São Paulo, v. 2, n. 2, p. 143-162, jul./dez. 2009.

MENDES, Camila Faccioni. Paisagem urbana: uma mídia redescoberta. São Paulo: Editora Senac São Paulo, 2006.

MIĖGE, Bernard. El espacio público: más allá de la esfera política. In: GAUTHIER, Gilles; GOSSELIN, André; MOUCHON, Jean (Orgs.). Comunicación y política. Barcelona: Gedisa, 1998.

MOLES, Abraham Antoine. O cartaz. São Paulo: Perspectiva, 1974.

REYES, P.; FRANZATO, C. Design para o território. CIPED 5 Congresso Internacional em Design. Anais. Bauru: 2009.

SANCHÉS, Fernanda. A reinvenção das cidades na virada de século: agentes, estratégias e escalas de ação política. Curitiba: Rev. Sociol. Política, 2001.

VERÓN, Eliseo. Esquema para el análisis de la mediatização. Diálogos de la Comunicación. Buenos Aires: Verón \& Asociados. Cultura y Comunicación, 1997. 